\title{
THE SOCIAL INTEGRATION OF BARREL CHILDREN IN CANADIAN SOCIETY
}

By

Andrea Denise Lawrence, BSW, Ryerson University, GRADUATION YEAR 2001

\author{
An MRP \\ presented to Ryerson University \\ in partial fulfilment of the requirements for the degree of \\ Master of Social Work \\ in the Program of \\ Social Work
}

Toronto, Ontario, Canada, 2019

(C) Andrea Denise Lawrence 


\section{AUTHOR'S DECLARATION FOR ELECTRONIC SUBMISSION OF A MRP}

I hereby declare that I am the sole author of this MRP. This is a true copy of the MRP, including any required final revisions.

I authorize Ryerson University to lend this MRP to other institutions or individuals for the purpose of scholarly research.

I further authorize Ryerson University to reproduce this MRP by photocopying or by other means, in total or in part, at the request of other institutions or individuals for the purpose of scholarly research.

I understand that my MRP may be made electronically available to the public. 


\title{
ABSTRACT \\ THE SOCIAL INTEGRATION OF BARREL CHILDREN \\ IN CANADIAN SOCIETY
}

\author{
Master of Social Work, 2019 \\ Andrea Denise. Lawrence \\ Program of Social Work, \\ Ryerson University
}

People migrate globally in search of better lives, and migration often produces political, sociocultural, and economic turbulence. This qualitative study explored the lived experiences of two Caribbean barrel children, whose mothers sought employment in Canada and abandoned or left their children in the care of family members. Data consisted of two daughters' stories daughters, which illustrate the complexities of the barrel-children phenomena. A narrative approach was used to collect the data, and theoretical frameworks guiding the study included Bowlby's attachment theory, Black feminism, and the intersectionality of race, class, and gender. Data analysis involved structural and narrative analysis. The study found that, in contrast to the literature, the two participants had positive experiences as barrel children and in reuniting with their parents in Toronto. The study highlights the importance of grandmothers in caring for children left behind and even after reunification with parents in Canada. The Black community, along with Black teachers, also play key roles in helping barrel children integrate into Canadian society and face challenges such as racism.

Keywords: Barrel children, Canada, Caribbean immigrants, Children left behind, Parental separation. 


\section{ACKNOWLEDGEMENTS}

I would like to take this opportunity to thank a number of people who supported me through my long and winding journey to attain one of my educational goals. I would like to thank my employer, particularly my previous supervisor Jim Langstaff, who was instrumental in helping me balance full-time work and school while encouraging me throughout the process. I also thank my professors at the Ryerson University School of Social Work, who helped me through tedium while being extremely patient. I would like to say a special thank you to Gordon Pon, my MRP supervisor, who helped grow through this process of completing the Major Research Paper. Thank you to all the people in my Ryerson cohort, my friends, parents, and my brother — who has been so understanding about everything I do. I would like to thank Junior Higgins, who echoed louder than me my lifelong deep desire to go back to school to do my masters and who had helped me every step of the way. To my girlfriend Liz Brown, who I have known since the first day of college and who has been the voice of reason and is witty beyond her biological years, thank you for providing cultural inspiration while helping me to focus on bigger goals! Lastly, I would like to thank the two participants, Doreen and Tammy (pseudonyms). Without their participation, this major research paper would not have been possible. 


\section{DEDICATION}

I am dedicating this Major Research Paper to my grandmother Victoria Lawrence, who passed away over 20 years ago; gone but not forgotten. She was the first person to introduce me to social work practice, in the small land-based community of South Manchester, Jamaica. This was long before social work became professionalized or a career I wanted someday to pursue. Affectionately called "Aunty Vicky" by everyone in the community, she would organize, volunteer, support, and intervene to bring the community together, especially around issues of social justice. Her passion for justice was transformative.

In addition, I would like to dedicate this MRP to the two participants in this study and to all immigrants who became barrel children because of global migration. 
TABLE OF CONTENTS

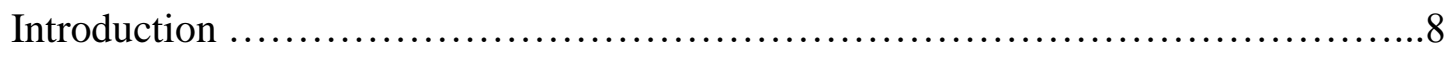

Literature Review................................................... 14

Theoretical Framework....................................................20

Methodology..........................................................29

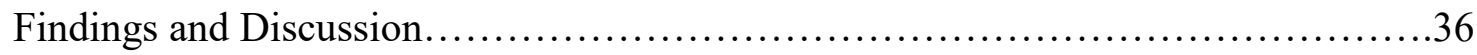

Conclusion..............................................................

Appendixes...........................................................58

References.............................................................65 


\section{LIST OF APPENDICES}

Appendix A - Recruitment Flyer

Appendix B - Interview Guide

Appendix C - Consent Agreement
Page 58

Page 59

Page 60 


\section{CHAPTER 1. INTRODUCTION}

Global migration is defined for the most part as a situation where people move from a developing to developed countries to look for employment (Conway, 1991). This migration has resulted in interesting shifts in human existence that bring some degree of turbulence and change to the political, socio-cultural, and economic landscapes. At the heart of this global dynamic is the movement of people in search of "a better life," primarily from an economic perspective. Global migration often has a number of unforeseen consequences, including but not limited to breakdown in the family structure through parent-child separation (Conway, 1991). In the Caribbean, migration is mostly for financial benefit and often takes the form of serial migration, in which parents' moves from the Caribbean to industrialized nations such as the United Kingdom, the United States, and Canada, while their children remain behind (Williams, 1985). Parents, most frequently mothers, leave their home countries with the intention of having their children later reunite with them in their new home, when the parents can afford to do so. While the parents' primary goal is to secure a better financial future for their families, their children are often left in the care of aunts, uncles, grandparents, community members, or friends. Parents, while trying to settle in the new countries, send back clothes and food to help with their children's material well-being, in a barrel.

The term "barrel children" was coined by Dr. Claudette Crawford- Brown of the University of the West Indies and suggests that the contents of the barrel often replaces the love and physical bond desired by the children (Crawford-Brown \& Rattray, 1994). The barrel becomes an indirect means of maintaining these long-distance relationships. The barrel is of great significance for most families in the Caribbean, particularly Jamaicans. Originally made of 
cardboard and recently upgraded to plastic, the barrel sends a bona fide message of love from migrant parents to their children left behind. The strategic choice of the barrel's contents, such as bars of scented soaps with a distinct foreign scent (particularly Irish Spring), provides an even more significant message, as the contents speak 'love' from a distance. The barrel further coveys an alluring message of better things to come when parents and children finally reunite. The bars of perfumed soap both offer comfort and provide a glimpse of a utopia (Crawford-Brown \& Rattray, 1994). Although barrels are sent throughout the year, for many of those left behind the Christmas barrel is a tantalizing prospect of temporary escape from the deeply woven feeling of emotional separation from their blood parents and their ever-present reality of their less affluent existence.

Emigration is not the only or even dominant reason why parents become separated from their offspring; broken marriages, death, and incarceration are others. Nevertheless, the impact of emigration on the life outcomes of barrel children has received significant attention within social science. Despite the wide body of literature in this area, research tends to be skewed toward the overall economic outcomes of immigrants. Limited attention has been paid to the specific issue of parental separation as a result of economic migration to more prosperous countries. The literature that exists suggests that there are huge social-integration challenges for adult children, particularly daughters who were left behind in countries like Jamaica and later unite with their mothers (Crawford-Brown \& Rattray, 1994).

This paper examines the impact of the barrel-children phenomenon on the social integration of women living in Toronto. A narrative approach was used to gather responses from the participants. In the narrative approach the respondents shared their lived experience and 
knowledge with the researcher, providing intricate details of their lives, in both Canada and Jamaica.

\section{Context}

The aim of the research were (a) to capture the participants' experience as barrel children living in Jamaica without their parents and (b) the challenges, benefits, assumptions, discourses, and stereotypes that relate to their social integration in Toronto. This research was of particular interest to me as well as to the participants, because I experienced parental separation and lived instead with extended family. My grandmother was the main maternal figure in the formative years of my life. The two participants, Doreen and Tammy (pseudonyms), brought their own divers lived experiences to the project, which enriched my understanding of the complexities of the barrel children phenomenon viewed through the lens of migration.

The study tells participants' stories of living in Jamaica and their transition and integration into Canadian society. It explores the stereotypes, challenges, and barriers they faced and how emotional separation from friends, family, and community affected them. Many community members from the Caribbean, particularly those of Jamaican descent speak openly about their migration process, which often starts with leaving children behind in Jamaica, who grow up with their grandparents. The stories are often told in Caribbean community spaces in Canada, either hair salons or community gatherings such as Nine Night. It is an informal gathering of family and community members after the death of a family member, usually held the night before the funeral. Stories of leaving children behind often highlights struggles with racism and the constant juggling of work with the obligation to take care of the children and family back home. 
Because I am a member of the Jamaican-Canadian community and as a result of my personal experience with parental separation and growing up with my grandmother, I have insider privilege (Dwyer \& Buckle, 2009). This is important to highlight, because aspects of identity can be explored through different lenses and sometimes confers power on researchers with insider privilege. I am a Black, able-bodied, cis-gendered female who spent most of her formative years in rural parts of Jamaica. Geographical location is one aspect of identity and can sometimes speak to different experiences of power, privilege, and oppression. One benefit of a researcher's insider status is that participants may feel more comfortable sharing their stories with someone who knows what they are talking about, uses language that is familiar to them. Insider status also helps researchers bring out specific nuances of participants stories as they relate to the phenomenon being researched. Insider status also helps democratize the research and dissolve the traditional boundaries between researchers and participants. Being able to involve community members fully in the research could break down some power imbalances.

Globally, immigration policy has largely aimed to satisfy demands in the labour market. Over the last five decades, there has been a significant increase in the number of Jamaicans migrating to industrialized nations, such as Canada, the United States and Great Britain who seek "better lives" for themselves and their children (Conway, 1991). One Canadian example of immigration policy aimed at satisfying labour-market demands was the West Indies Domestic Scheme (WIDS). This was an agreement between the Government of Canada and Englishspeaking Caribbean countries (Ferguson, 2007). Jamaica is a former British colony and, after independence from Britain, it was unable to support the high number of unemployed people in the 1970s. WIDS, along with the Overseas Domestic Farm Worker Program, provided Jamaicans an avenue for external employment while bringing much needed monetary 
remittances into Jamaica (Hsiung \& Nichol, 2010). Both programs strictly restricted migration of entire families to Canada, resulting often in parents being separated from their children for an extended period of time. Children were then raised by other family members, such as aunt, grandparents, and older siblings.

Parents working in Canada routinely shipped barrels filled with consumer goods to Jamaica for their children left behind. The contents of these barrels became a metaphor, and often a literal replacement, for emotional and physical bonds between parents and their leftbehind children (Crawford-Brown \& Rattray, 1994). The term "barrel children" was coined by Dr. Claudette Crawford- Brown of the University of the West Indies, who conducted a significant amount of research on this topic. Barrel children in Jamaica sometimes reunited with their parents after many years apart, often in their early teens (Crawford-Brown \& Rattray, 1994).

This research project focuses on the mother-daughter relationship from the daughters' perspective. A narrative approach was used to capture the in-depth stories, counter stories, and emotions associated with being a barrel child. This major research paper aims to address knowledge gaps in the literature by adding two new dimensions: (a) daughters' perspective on the impact of separation on the mother-daughter relationship and (b) challenges and strengths evident in concrete examples of barrel children's experiences. Further, this MRP challenges Eurocentric theoretical paradigms and understanding of child development and attachment. This study will assist social workers, psychologists, teachers, and other community partners to understand clients in communities where there is a high concentration of Caribbean immigrants, particularly from Jamaica. This study will help guide their understanding of the different 
subcultures within the broader Jamaican-immigrant culture and help them engage with Caribbean families.

This major research paper begins with a review of the existing literature about barrel children. Chapter Two presents the theoretical frameworks are described: Bowlby's attachment theory; Black Feminism; and the intersectionality of race, class, and gender. These interwoven theoretical frameworks inform and shape the conceptualization and undertaking of the research. Chapter Three is the methodology section and provides a synopsis of the narrative approach, data collection, profiles of the participants, and data analysis, and discusses ethical issues and the limitations associated with the research. Chapter Four presents the research findings, data interpretation, and implication of the study for social work practice are discussed. The final chapter concludes with a final assessment and the findings of the phenomena. 


\section{CHAPTER 2. LITERATURE REVIEW}

In researching the barrel children" phenomenon, I searched for peer reviewed articles in the following electronic databases: EBSCO, PsyINFO, ProQuest, Google Scholar, and United Nations International Children's Emergency Fund (UNICEF) website. I used the search terms 'migratory separation,' 'serial migration', 'children left behind,' and 'barrel children.'

The Caribbean has high levels of both interregional and international migration. UNICEF (2009) estimated that the net migration rate from the Caribbean is one of the highest in the world, with international migration being the dominant form. This dominance is reflected in the large diaspora community, particularly in North America and Europe (Thomas-Hope, 1992). The impact of this outmigration has received some attention within the empirical-research literature; however, the research I found focuses largely on economic challenges and benefits, with less attention to the effects of separation on children left behind when parents migrate.

UNICEF (2008) estimated that about 10 to $20 \%$ of children in the Caribbean, particularly Jamaica, do not reside with at least one of their parents as a result of international migration. One study compared these findings to families in Mexico and found that children born in twoparent Mexican families have a migrating father at some time in their childhood (Cortes, 2008). The limited research about barrel children suggests that, for some children, parental separation may result in emotional, psychological, behavioural, educational, and health challenges. Cortes' (2008) findings are comparable to studies conducted in Asia, Africa, and China that point to the aftermath for some children and the need to address the effects of parental separation on children (Cortes, 2008). Regardless of which parent migrates, children's physical and emotional health, and social wellbeing are impacted. The studies that I reviewed from outside the Caribbean suggested that the effects on children in the home country differed, depending on the country and 
gender of the migrating parent, with outcomes being better in some countries than others. For example, in Jamaica when fathers leave, studies focus more on the issue of remittances and the vulnerability of female-headed households (UNICEF, 2008).

Within literature on the barrel children phenomenon there is limited research on the emotional effect of parental separation on adult children and their social integration into the host countries. Larmer (1996) examined the phenomenon by providing context for most families, indicating that migrants' main reason for going to the United States or Canada is to improve their family situation. The study found that there are more opportunities for women than men. Women mostly find work as domestics (usually as housekeepers or baby sitters) or as factory workers (Larmer, 1996). There are instances where fathers migrate first and later send for their families however, with mothers, migration is usually meticulously thought out. This is because it is important for the parent most likely obtain employment to migrate first, and plan to send for the family members who remain. More often than not, it is mothers who are more likely to find jobs as domestics and thus migrate first. Therefore, the chance of children being separated from their mothers, not fathers, greatly increases. Women are leave their children behind to gain employment in industrialized countries and help their families financially. The children are often left with fathers, aunt, uncles, grandparents, close friends, or whoever will assume the responsibility (Larmer, 1996). Leaving children behind happens in most countries where there is a vast amount of emigration, such as Mexico and China (Larmer, 1996).

McCarty (2004) reveals that, although some immigrants in the United States of America function at a high level, it is with tremendous effort that they are able to do so. Immigrants in McCarty's study talked about their struggles as children adjusting to American life, their experience of being separated from parents, or being raised by relatives while their parents lived 
in the United States. Some immigrants have survived the trauma of moving from family to family after their mothers left for the United States. There were some experiences of family violence, verbal, and physical abuse when they were moved from home to home. Others had mixed feelings and, although the separation from parents was painful, their experiences with caregivers were positive (McCarty, 2004). One woman spoke about her very positive experience of residing with her great-grandmother for the first 13 years of her life, after her mother migrated to the United States. She attributed the "careful upbringing" to a great grandmother who loved her and lived until she was about 111 years old (McCarty, 1998),

Crawford-Brown (1999) compares barrel children to the street children of many developing countries. She remarks that they are virtually invisible to the broader society. They will often stay with families, and their absent parents keep them fed and clothed by sending barrels of goods and money several times a year. She mentions that affluent parents sometimes give children cellular phones so that they could maintain phone contact. She mentions further that some barrel children are often obsessed with status in relation to their peers (CrawfordBrown, 1999). They wear expensive clothing, which most of their peers are unable to afford and often link the clothing to their parents in the United States or Canada. This practice does not depict the hard and horrid realities of immigrant life; instead it romanticizes their parent's lives abroad. According to Lamar and Smith, (1996) some barrel children are literally abandoned. Prolonged separation from their mothers and waiting to reunite with them can be traumatic for these children. Added to the trauma is the lack of parental supervision, which makes some children vulnerable to severe behaviour problems. In another study, Crawford- Brown (1997) found that about $60 \%$ of delinquent adolescents at two correctional facilities in Jamaica had 
mothers who had migrated. She also noted that these children are often starved for affection, and therefore gangs become an attractive alternative.

According to Smith, Lalonde, and Johnson (2004), children who were separated from their parents as a result of migration disclosed greater attachment to their substitute caregivers than with their parents at reunification. At that time, the older children exhibited more problems than the younger ones. Smith, Lalonde, and Johnson report that barrel children had the same characteristics as children in foster care, suggesting that Caribbean children whose mothers migrate to other countries could experience multiple separations. A child may move several times because of death or illness of a caregiver, conflict between mother and caregiver, or when children are left with their fathers and a new partner assumes the caregiving role. Like foster children, these children experience instability due to multiple placements (Smith, Lalonde \& Johnson, 2004).

Pardeck's (1984) findings highlight the instability of children who are placed in foster care and connect the experience of multiple placements to their emotional and behavioural outcomes. Pardeck's study revealed that children who experience instability in foster care are often involved with the legal system. Adams (2000) examined the psychological consequences of separation and reunification, due to migration. The case study concerned a boy who was separated from his mother at the age of 18 months and later reunited with her at the age of 8 . The family dynamics were impacted by separation, and clinical intervention strategies were explored. The parents struggled to adjust to the reunification and the parents found it difficult to set boundaries for a child with whom they had little or no relationship. Adams found that building familial relationships after reunification is an enormous task, which most migrant parents in the host country were unprepared for. Among some Caribbean families, separation and reunification 
are defining characteristics. According to Adams (2000), this family reconfiguration usually follows migration to escape socioeconomic conditions that continue to plague the Caribbean. $\mathrm{He}$ also notes that the narrative of leaving the family for a "better life" is entwined with the history of migration.

Macklin (1991) highlights that, after the Second World War, Canadian immigration policy focused on attracting Caribbean women, not men, to fill low-paying jobs as domestics. Caribbean women's labour was sought to substitute for middle-class Canadian mothers who moved to paid work outside the home. In order to make the migration offer more attractive, the Canadian Government added a promise to allow Caribbean domestics to remain in Canada, only if they fulfilled their domestic-work contracts (Macklin, 1992). Racist beliefs about the sexual behaviour of Caribbean women motivated the Government to require migrants to undergo gynecological examinations for venereal disease when they arrived (Macklin, 1992). Despite the low wages and poor working conditions associated with domestic work, many Jamaican women opted to take them rather than be unemployed in Jamaica. Prior to globalization, this choice set a precedent for a rich developed county like Canada to create a private class of servants for white employers. The wide-scale exploitation of Third World domestic workers through their construction as non-citizens later became a key to globalization.

Despite Jamaican women's educational attainments and work experience before migrating to Canada, being domestic workers reinforced a racial stereotype of Jamaican women as inferior to white Canadian women, and only capable of jobs not requiring a high degree of education (Macklin, 1992). In contrast, many educated women took domestic jobs, leaving their own children behind in the care of others and spending their meagre earnings on barrels of household goods and food back to their families. 
Bakan and Stasiulis (2003) highlight that, while Jamaican women were welcomed temporarily to Canada as a source of cheap labour, their colour made them largely unwelcome as permanent citizens, in the eye of the largely white Canadian population and its federal government. These women quickly learned that racial discrimination was often overt in Canada and certainly an everyday fact of life. One example of this discrimination against Black women was the federal government's decision in the 1980s to allow other supposedly better educated, non-Black women from the Philippines and other parts of Asia to migrate for domestic work.

According to Hsiung and Nichol (2010) in their examination of the policies and experience of foreign domestic workers, Jamaican women working as domestics in Canada were noncitizens deprived of the same rights as Canadians. Much like migrants to Canada under the Temporary Foreign Worker program, they were often subjected to abuse, violence, and humanrights violations. Caribbean women, primarily those from Jamaica, reacted to the racism in Canadian society by disputing their position through anti-racist organizing and advocating for greater citizenship rights within Canada's social, economic, and political structures. 


\section{CHAPTER 3. THEORETICAL FRAMEWORK}

While I found no theories in reviewing the literature that focus specifically on parental separation of barrel children and related migration, most of studies employed Bowlby's attachment theory or Grinberg and Grinberg's (1984) psychoanalytic perspective on migration. Bowlby's theory is world famous; like Freud, he was a psychoanalyst and believed that mental health and behavioural problems could be attributed to early childhood. Bowlby (1907-1990) developed his theory in Britain, in attempting to understand distressed infants who had been separated from their parents (Cassidy et al., 2013).

Bowlby's (1973) attachment theory emphasizes the importance of each infant having a sensitive, responsive, and consistent caregiver. Distress is evident among young children who experience physical separation from caregivers; it results in anxiety, fear, anger, and sadness. Among older children, lengthy absence, poor communication, and signals of abandonment or rejection can compromise the bonding process between caregiver and child (Bowlby, 1973). Bowlby suggests that the attachment bond plays a significant role in providing emotional support throughout an individual's development. This support is especially needed during life transitions and forms the foundation for other affectional bonds. Bowlby theorizes that a child initially forms only one attachment and that the attachment figure acts as a secure base for exploring the world. Because the attachment relationship is a prototype for all future social relationships, disrupting it can have severe consequences. Although Bowlby does not mention the possibility of a child developing other attachment figures, he believes that the primary bond is with the mother and this bond is much more important than any other bond. Because this attachment qualitatively supersedes all other relationships, any subsequent relationship means a breakdown of the 
maternal attachment. According to Bowlby, this breakdown leads to serious negative consequences, such as delinquency, reduced intelligence, increased aggression, depression, and affectionless psychopathy.

Grinberg and Grinberg (1984) examined the effects of immigration from a psychoanalytical perspective. Their study explored both normal and pathological reactions to migration. Unconscious processes are activated in individuals who face the challenge of leaving familiar worlds behind and adjusting to new and unfamiliar situations (Grinsberg \& Grinberg, 1984). They discussed the role that the language and age of the child who is migrating play in process of adjusting to parents after migration. They focused on the special problem of exile from one's country of origin when involuntarily leaving a country of origin and whereby return is impossible. Grinberg and Grinberg (1984) use imaginative analogies to highlight the effect of migration on human development: They view migration as a series of arrivals and departures. They also look at the difference between migration and adoption, which both involves profound dislocation (Grinberg \& Grinberg, 1984). The effects of dislocation on the migrant's sense of identity are also considered. The authors contrast the effects of migration and adoption on human development. Comparing adopted children with immigrants, they conclude that adopted children, who once had parents, now live with others who are not their biological parents and are placed in situations that, in many respects, mirror the immigrant experience.

According to Grinberg and Grinberg (1984), migration can awaken anxieties such as "persecutory" anxiety in the face of change; "depressive" anxiety, in which migrants mourn the loss of those left behind and lost parts of the self; and "confessional" anxiety over distinguishing between the old and the new (Grinberg et al., 1984, p.13). They view anxiety as a constant feature of the migratory process. The three types of anxiety, together with symptoms and the 
defence mechanisms they may produce, comprise the psychopathology of migration. Defence mechanisms are psychological strategies that people unconsciously use to protect unacceptable thoughts or feelings of guilt, denial, and in some cases displacement (Grinberg \& Grinberg, 1984). The study revealed that, at present, determining the effects of migration on children is much more complex than the effects on adults. Grinberg \& Grinberg (1984) highlight that the trajectory is different if the family migrates together rather than alone: the adults act as shock absorbers for their children, although they themselves are unsettled by the same migration (Grinberg \& Grinberg, 1984). The author highlighted further that young children who emigrate are deeply affected by the absence of people in their former social environments; specifically, friends, classmates and teachers, grandparents, aunt, uncles, and neighbours. Clinical examples were used to highlight the effects of children's loss. They were unable to express sorrow and, instead, expressed anger. The researchers mention an incident where a 6-year-old immigrant boy spoke openly about how much he missed his friends and burst into tears, decrying his migration as "Shitty" (Grinberg \& Grinberg, 1984). The boy immediately associated the two principal sources of his anxiety, acknowledged his loss of friends as well as the fact that his parents had not yet recovered from the economic regression into which they plunged after migrating. Of note is that the parents were unable to help their son, as they needed help themselves (Grinberg \& Grinberg, 1984) According to the authors, these anxieties, together with the symptoms and defense mechanisms they may produce, comprise the psychopathology ${ }^{1}$ of migration. Bowlby (1973) asserts that attachment theory and child development frame the understanding of children's responses to separation from their mothers. Bowlby's attachment theory first appeared in 1973. His theory is widely used in social work practice to account for the effects of maternal

\footnotetext{
${ }^{1}$ Psychopathology refers to mental distress or the manifestation of behaviors and experiences that may be indicate mental illness or psychological impairment.
} 
separation on young children and the importance of reuniting them. Attachment theory states that the nature of children's attachment with their mothers has profound effects on children's subsequent development. Bowlby (1973) uses the term "mother figure" to assert the belief that the child's principal caregiver in infancy and early childhood is most likely to become the child's principal attachment figure and most important influence on subsequent development.

According to Bowlby (1973), attachment is more than the expression of behaviour; it is an internal representation of the characteristics of a specific relationship. The parenting relationship can also be understood as an elaboration of attachment. For example, adults who experienced a secure attachment in their own infancy are more likely to be able to comfortably respond to their children (Bowlby, 1973). Adults whose attachment was insecure or disorganized, or even hostile, are more likely to have difficulty coping successfully with young infants' needs (Bowlby, 1973). This implies that the quality of adults' parental behaviour is determined solely by the quality of their childhood attachments. Attachment theory asserts that attachment bonds play a significant role in emotional support throughout an individual's development. This support is especially evident during life transitions and forms the foundation for other affectionate bonds.

While Bowlby's attachment theory is one of the theories that comprise my theoretical framework, it has limitations. As both descriptive and explanatory language of reproduction and child development, attachment theory is underlain by whiteness. It also carries a legacy of sexism and is not always helpful in understanding the experiences and issues of motherhood for women from diverse backgrounds. Rather, it applies a white, heterosexual understanding of motherhood that erases all other mothering arrangements, such as "other mothering." 
James (1993) defines other mothers as "those who assist blood mothers in the responsibilities of child care for short-term to long-term periods in order to relieve informal and formal arrangements. This can be, but is also not confined to, blood relatives such as grandmothers, aunts, sisters, cousins, or supportive fictive kin” (p. 47), especially in AfricanAmerican, Caribbean, and Indigenous communities. Bowlby (1973) assumes that children need to have one caregiver, particularly a woman, so they can grow up and be productive citizens. I refute this assumption: in my experience, there is no evidence to support it. In fact, it minimizes other caregiving arrangements, such "other mothering" and "customary care." The latter is an Indigenous arrangement that racialized people embrace, and it does not follow Bowlby's assumptions. Instead, it embraces multiple caregivers and does not presume that having multiple caregivers greatly diminishes attachment, as Bowlby does. On the contrary, customary care helps children to become strong, independent, and resilient adults.

Stasiulis and Bakan (2003) highlighted how the flow of Jamaican migrants became predominantly female in the mid-20th century. They used the "feminization of migration" framework to examine the differences between the societies Jamaican women migrated from and the host society. This framework is supported by Black feminist theory, which argues that sexism, class oppression, gender identity, and racism are inextricably bound together. The way these concepts relate to each other is called "intersectionality." This term was first coined by legal scholar Kimberlé Crenshaw in 1989. Crenshaw (1989) argues that the experience of being a Black woman cannot be understood only in terms of being Black or being a woman. She points out that the feminization of migration has provided fertile ground for the reinforcement of transnational communities, since most of the women who migrate for employment, leaving their families behind, have been Black (Crenshaw, 1989). 
Most of these women migrated, never to return to Jamaica, and established new lives in host countries such as Canada and the United States of America. As described earlier, many were mothers who left their children behind in the care of grandmothers or other older female relatives. The only contact between mother and child would be the barrels of goods sent to the Caribbean barrel children (Crawford-Brown \& Rattray, 1994).

After these migrant women settled into their new countries, they often sent for their children. This reunification was often problematic, because mothers were like strangers to their own sons and daughters after prolonged separation (Seaman, 2011). As a result of growing up without their mothers, these children became more independent. This outcome run counters to arguments in Bowlby's (1973) attachment theory that lack of maternal attachment negatively affects children's development.

In contrast to Bowlby's dominant Eurocentric ideology, Black feminists struggle to have their voices heard in formal or informal settings. The intersectional theory of critical and structured patterned narrative, which links race, class, and gender inequality, interrogates Eurocentric school of thought as it relates attachment theory and parental separation. From the standpoint of Black feminism, Black women's everyday experiences not only provide a unique lens for understanding self, community, and society, but also enable Black women to challenge and interrupt the dominant discourse of Black womanhood (Collins, 1993). According to hooks (1987), feminist theory on "mothering" is racially codified. Mothers and mothering make possible the physical and psychological well-being and empowerment of children in AfricanAmerican communities. Through this well-being and empowerment, mothering, has great cultural and political importance, and as a consequence motherhood is a site of power for Black women (hooks, 1987). Mothering is the key link to the Black feminist transformation, both 
academically and politically. It also empowers "other mothers" (James, 1993), who accept responsibility for children that are not biologically related to them. In contrast, community mothers often take care of the community. These are women who, often past their childbearing years, choose to share their love with children in need. James (1993) argues that other mothering and community mothering both developed from a West African communal lifestyle and their interdependence on communities.

Collins (1993) argues that the dominant ideology of the slavery era socially constructed and controls images of Black womanhood, to reflect the dominant group's interest in maintaining Black women's subordination. Collins gives four examples of these carefully crafted images: the mammy, matriarch, welfare mother, and Jezebel. The matriarch, for example, "symbolizes the mother figure in Black homes. Just as the mammy represents the 'good' Black mother, the matriarch symbolizes the 'bad' Black mother. Spending too much time away from home, [the matriarch] ostensibly could not properly supervise her children" (Collins, 1993, p. 69). The matriarch is an employed, overly aggressive, unfeminine, and emasculating, failed mammy (Collins, 1993). These stereotypes assume qualities to justify Black woman's oppression. Nevertheless, Collins argues, Black resist these derogatory stereotypes by countering them from a standpoint that is rooted in their own experiences and mothering traditions.

Stack (1975) highlighted how important and central extended kin are to the Black community, especially in poor urban families. She argues that Black families often extend beyond the walls of their households. In Gibson's (2000) study of grandmothers, she found that grandmothers and great-grandmothers play an integral role in parenting for Black families. Increasingly, African-American grandmothers have replaced parents absent as a result of social problems. Grandmothers' role in parenting can be traced back to Africa. Wane (2000), in her 
research on women in pre-colonial Kenya, show how beliefs and customs gave rise to communal childrearing and understanding that parenting, especially mothering, was integral to African traditions and cultures. She explains that pre-colonial Africa was founded on and sustained by collectivism. Labour was organized nonhierarchically, giving equal value to men's and women's work. Social organization within families was based on the principles of patrilineal or matrilineal descent, or a combination of both. Mothering was a collective activity. Today in Africa, the practice of other mothering provides multiple role models for children as well as keeping the traditional African value system of communal ownership and sharing alive. Wane concludes that this collective form of mothering helps the community to nurture themselves and future generations.

Other mothering provides an Afrocentric lens on parenting, rooted in an African worldview that can be traced through slavery and developed in response to a need to share the responsibilities of child nurturance. Slavery saw the translation of other mothering to new settings, since Black women were expected to care for slave owners' children in addition to working in the house and the fields (James, 1993). The unpredictable nature of slavery engendered the Black community's need to foster children whose parents, particularly mothers, had been sold.

While mothering in the traditional sense involves nurturing one's biological offspring, it is also common for African-American women to nurture other's biological children (James, 1993). According to (Collins, 1993), historically, the value African-American communities place on "other mothering could highlight fundamentally different beliefs about parents" role than those assumed in nuclear families" (p. 131). Rather than believing that parents have ultimate responsibility for their own children, other mothering reflects an assumption that individual 
parents have the "right" to parent children as they see it fit. African-American communities believe that other mothers - the kin, fictive kin, and community members who help raise children—also have rights in child-rearing. Some researchers working with Bowlby's (1973) attachment theory have found that mothers in different cultures understand their children's attachment-related behaviors in fundamentally different ways. However, scholars such as Bowlby, Grinberg, and Grinberg have not considered how these different ways might lead other mothers in different cultures to different understandings of their roles in child rearing.

Historically, African-American women have grown up valuing networks of caregivers; they participate more actively in their communities and respect the roles that other mothers play. Collins (1993) describes the practice of other mothering as women-centered networks that are fluid and changing, depending on the needs of a given family. In such circumstances, fluidity occurs within particular relationships. For example, the relationship between a blood mother and her child must adjust as the mother's working conditions change. When attachment theorists write about dynamics, they typically refer to changes from one relationship to the next. This approach assumes that stability is central to development. Collins (1993) points out this key weakness of attachment theory. She suggests that theorists should think about intrarelationship dynamics, in addition to thinking about changes from one relationship to the next. Collins provides a rich historical account of how sharing child-care responsibilities shaped communities and mothers, and how this helps children to understand the world from a different vantage point. 


\section{CHAPTER 4. METHODOLOGY}

A narrative approach was used in this study to capture the participants' intricate experiences of living in Jamaica and later joining their parents in Toronto. Connelly and Clandinin (2000) argue that "narrative is the best way of representing and understanding experiences" (p.18). The narrative approach examines stories of the lived experiences of an individual or small group of people, and the meanings that individuals give to a particular experience (Creswell, 2007). The narrative approach does not require a large sample and is best suited for gathering intricate, comprehensive stories from participants (Creswell, 2007). Narratives, or stories, are personal accounts of the significant aspects that participants use to make sense of their experiences. Stories are also an important aspect of Black feminist thought (Amoah, 1997). It is critical in challenging race, gender, and class oppression while empowering African-American women. Black feminist thought argues that "Oppressed people resist by identifying themselves as subjects, by defining their reality, shaping their new identity, and naming their history, through telling their stories" (Amoah, 1997, p. 1). Storytelling can be traced back to West African culture and grandfathered to current African-American and Caribbean cultures. The tradition was based on the passing on of wisdom and functions to amplify the voices of oppressed people.

As a black Caribbean woman, my daily life is entwined with theory, even when the word is not mentioned. Black feminism helps to create and theorize black people's experiences of intersectional oppression and remove them from the marginalized position that the dominant society uses to regulate them. A key strategy for people who exist on the margins, particularly Black women, is resistance. As they try to survive amidst oppressive structures that seek to destroy their humanity, Black women use Black feminist thought to formulate and reclaim empowerment. As previously mentioned, Black feminism guided this research. I chose this 
theoretical framework because it provides context for collective struggles while addressing the intersectionality of Black women's oppression.

One aspect of narrative research is "counter storytelling," which is telling the stories of people whose experiences are often untold. Counter storytelling can be used to expose, analyze, and challenge deeply entrenched narratives characterized by racial privilege (Solorzano \& Yosso, 2002). The significance of counter storytelling is that it was used to challenge hegemonic, racist discourse that dominates research. It is also a method of giving voice to individuals who are often silenced. This was a useful mechanism to challenge and change racial dominance while furthering the dismantling of oppressions. Counter story also provided a platform for historically marginalized groups to explore concerns about voice and positionality, and the racist practice of telling stories using dominant discourses. Counter story challenges hegemonic, racist discourses that often reflect the voices of white, upper-class, heterosexual men. These men use their experiences as a normative point of reference for all other people's experiences, especially in research.

The narrative interview should be viewed as a conversation and a partnership between researchers and research participants (Clandinin, Connelly, \& Riessman, 2008). The narrative approach requires researchers to let participants direct their interviews and tell their stories (Riessman, 2003). Researchers must recognize the key role they play in constructing interview data; that is, the participants' stories (Riessman, 2003). Ultimately, researchers present the participants' stories and should ensure they are not misrepresented (Riessman, 2003) by making interviews unstructured, informal dialogues. In this study, the measures I took to accurately represent participants' stories included using both English and Patois (pat-wah) to ensure that I captured participants' thoughts, feelings, and opinions veraciously. 
In this study, I used counter storytelling as an approach to present the participants' stories. Counter storytelling originated from critical race theory, which began around the mid1970s. Solórzano and Yosso (2002) define counter storytelling as "a method of telling the stories of those people whose experiences are not often told" (Solorzan \&Yasso, 2002, p. 33). Counter stories expose and challenge deeply entrenched narratives and characterizations of racial privilege, sex, etc. In this sense, counter stories can promote social justice by putting a human face on the experiences of often-marginalized groups. In this study, I used a form of counter storytelling called "Other People's stories or narratives" (Solorzano \& Yasso, 2002, p. 33). This type of counter story uses a third-person perspective to explore the experiences of individuals (Solorzano \& Yasso, 2002). Counter-stories look at their sense of social, political, and cultural cohesion and teaches others about research participants' social realities.

There are four functions of counter stories. First, they can help to form alliance among communities and people who are marginalized (Solorzano \& Yasso, 2002). Second, counter stories attempt to debunk the notions that dominant societies often have about marginalized and oppressed people (Solorzano \& Yasso, 2002). Third, counter stories can expose new realities for marginalized and oppressed individuals (Solorzano \& Yasso, 2002). Fourth, combining counter stories and present realities can build a world with more knowledge about peoples' lives than either element on its own (Solorzano \& Yasso, 2002). Counter storytelling is rooted in reality and does not tell the story from the teller's imagination. Instead, the teller breathes life into the plot, which involves characters and situations from everyday experiences (Solorzano \& Yasso, 2002). In this study, counter storytelling helps to explain the current everyday experiences of barrel children and their social integration as adults into Toronto society. Their counter stories examine, reveal, and challenge mainstream views of racially marginalized people. 
Mainstream stories about racialized people often emerge from the history of white supremacy and become the dominant narrative that transcends generations and cultures. It is important to acknowledge the power of white privilege and white supremacy in producing dominant narratives, especially in social science research. In most cases, it ignores race and other intersectional oppressions. Solorzano and Yasso (2002) argue that "storytelling is racialized, gendered, and classed and these stories affect racialized, gendered, and classed communities" ( $p$. 31). Another significant aspect of counter stories are their ability to be sensitive to the phenomenon being studied. Solorzano and Yasso (2002) name this "theoretical sensitivity," which they describe as a personal attribute of researchers. It is "having insight, the ability to give meaning to data, the capacity to understand, and capability to separate the pertinent from the impertinent information. This is important because it allows the researcher to enhance their awareness and further develop their research" (Solorzano \& Yasso, 2002, p. 33).

The three main research questions that guided this study were as follows:

1. How do adult barrel children experience separation, specifically during and after their separation from their mothers?

2. After reunification, what are some of the experiences within the mother-daughter relationship?

3. What are some of the challenges that adult barrel children experience in integrating into Canadian society?

In the study, I aimed to uncover diverse perspectives on adult barrel children's challenges, acceptance of their experiences as they integrated into Canadian society and to link these challenges and experiences to broader structural institutions. 
For the purpose of recruiting participants, I created a recruitment flyer (see Appendix A). Once I received approval from the Ryerson Research Ethics Board, I contacted local community members via email and flyers, asking them to pass the recruitment invitation to other community members with whom I did not have direct relationships. This was snowball sampling, which is also known as chain-referral sampling. It is a nonprobability sampling technique used when current participants recruit future participants from among their acquaintances (Creswell, 2007). This allows the sample group to grow like a rolling snowball. As the sample increases, enough data are gathered to be useful for the research. Snowball sampling is mostly used when participants who match the study selection criteria are rare (Creswell, 2007). In this study, I had difficulty recruiting members from the community, as members of marginalized communities are sometimes reluctant to engage in research, because they feel that their communities are over researched and that research makes little or no change to their individual situations or the community's.

Selection criteria included self-identifying as a Jamaican immigrant; living in Toronto; being 18 years or older; having parents who migrated from Jamaica, leaving their children in the care of family members; and later reuniting with their mothers in Canada. Once recruitment was complete, I negotiated one-to-one interview locations, dates, and times with participants. Although three adults were recruited only two were interviewed, as one participant could not because of her work schedule.

Unstructured interviews were conducted separately, using an interview guide (see Appendix B). This type of interview is widely used in research, because, while prepared questions can be changed to allow for new ideas and topics to surface during the interview process, the structure still allows the researcher to have a guiding set of issues to explore 
(Whiting, 2008). The semi-structured interview also allows in-depth conversations with research participant about their experiences. Before each interview, I gave each participant a consent form (see Appendix C) to sign, which provided permission for their voices and stories to be recorded. All questions were open ended, which allowed participant to elaborate on their responses to the questions.

All transcripts were transcribed verbatim, after which I went through the transcripts line by line to ensure accuracy. I utilized a restorying approach. Creswell and Poth (2018) explain that restorying involves the researcher retelling the story participants have shared with them. This approach can feature or highlight key milestones in a person's life and/or present a chronology of central events in the life of the participant. For example, restorying can resemble a narrative that includes a plot, time, place, and scene, Creswell and Poth note that from a postmodern perspective restorying can capture contradictions and challenge problematic dichotomies and silences. The restorying process also lends itself to carefully focusing on language and discourse, while probing for the meaning of words and phrases. This includes noting pauses, silences, and laughter. Any of these may indicate barriers in expressing what participants want to say (Riessman, 2003). I took all of these non-verbal behaviours in consideration in analyzing the transcripts, to fully capture the meaning and understanding of participants' experiences. These non-verbal cues may be missed if the analysis focuses only on what participants say instead of examining how they tell their stories (Riessman, 2003).

The social and legal risks of the study for participants were very minimal, because of the ongoing dialogue and safety measures in the study design, put in place to protect confidentiality. However, participants were at some psychological risk: the interviews may have unearthed buried emotions when participants talked about the separation from their mothers. This risk was 
managed by providing participants with a list of local social services agencies, in the event that they wanted to speak to someone about issues brought up by the interviews. The social risk was managed by ensuring audio and visual privacy during the interviews. Legal risks were managed by clearly-reviewing the information in the consent forms and verbally explaining that participation in the study was voluntary. I also told participants that they had the right to stop the interview at any time and ask that the recording be destroyed.

Pseudonyms were used to disguise the identity of each participant and to maintain and respect their confidentiality and privacy. To keep information provided confidential, no personal information about participants is included in this report. All demographic data is stored securely in password-protected files, and data printouts are stored in a locked location to which only I have access. The information will be destroyed within six months of the completion of the research. The data will be destroyed after a period no exceeding two years after completion of the research study, and the audio recordings will be destroyed six months after the Major Research Paper is submitted. The findings will be made available to Ryerson University and to any member of the Black community who wants to use them for further study of barrel children. 


\section{CHAPTER 5. FINDINGS AND DISCUSSION}

The participants' age ranged from 40 to 50 years. One migrated in the 1970s at age six, while the other migrated in the 1990s in her early teens. Both women identified as heterosexual. Both were raised as Christian, although one now does not identify that way. She has embraced Rastafarianism and identifies as more spiritual than religious.

The women are from rural parts of Jamaica, a Caribbean island nation that is part of the Greater Antilles. The island, 10,990 square kilometres in area, lies about 145 kilometres south of Cuba, and 191 kilometres west of Hispaniola. Jamaica has three counties: Middlesex, Cornwall, and Surrey. Within these counties are parishes. Both women lived in the county of Middlesex, in two separate parishes, before migration. One participant grew up in St. Catherine, a parish that holds a lot of colonial history and formally hosted the capital, Spanish Town. It is one of the island's largest economically viable parishes and is located on the south eastern part of the island. She described the small district within the parish where she lived as a bauxite-mining community, and most people worked in the mining plants. The other participant lived in the county of Middlesex's parish of Saint Ann. It is the largest parish in Jamaica and is situated on northern side of the island, halfway between the island's western and eastern ends. Slaves worked on coffee plantations in the parish. One participant described the small district where she lived before migration as "land based", because most people are economically sustained by farming. She recalls her grandmother telling her that many other people in the community had acquired the land they lived on after emancipation, when ex-slaves became independent coffee growers.

Both participants migrated to the Greater Toronto Area and have not since lived outside it. Although, one participant indicated that, even though she bought a house in Brampton five 
years ago, she had lived most her life in Toronto. Both participants are college graduates and work in their fields of study. One works in the travel industry, and the other in education. Both participants resided with their grandmothers and extended family members when their mothers migrated to Canada. They both experienced prolonged separation as a result of migration. Some of the literature I reviewed indicates that children suffered physical abuse, and others sexual abuse, at the hands of trusted family and community members after being left behind by parents.

The two participant I interviewed, however, did not mention any experience of physical or child sexual abuse but said that their experiences were positive and that they were well taken care of. They reported that their caregivers in Jamaica, mostly their grandmothers, were physically and emotionally available, possessing traits of a good mother substitute. One participant mentioned that the only difference with her household was that her mother was not present, but her grandmother continued to uphold the matriarchal role and was the glue that kept the family together. Empirical evidence supports this positive outcome: being left behind cultivates attributes such as resiliency, especially when they are left in the care of people such as grandmothers and extended family members who love them (Chamberlain, 2001). This resilience is documented in some of the articles I reviewed for this study.

\section{Tammy}

As Tammy recounted,

My grandmother took care of me, and I don't remember when I did not have her as my caregiver. She took care of us, everything I know I learnt it from my grandmother. When I was upset and sad, she was there to 'hush it back.' She always had time for me.

Tammy is a 43-year-old woman, born in Saint Ann, Jamaica. She said that, before her mother left for Canada, she was a farmer who raised animals and sold them at the local market. Her mother was always home when Tammy arrived from school and would often spend one-to-one 
time with her while she completed her homework. Attending church was another big family event, not just with her family but with other members of the community. Tammy's mother was also active on the local community council, which helped to plan community events such as the summer fair at the local community center. Her father resided in another district and she rarely saw him, as he did not play an active physical role in their lives; however, he supported them monetarily.

Tammy is the eldest of three sisters. Her mother left for Canada when Tammy was nine years old. Upon arrival in Canada, Tammy's mom took a job as a nanny and resided in Toronto. Tammy reunited with her after six long years, at the age of 15 . Tammy does not recall if there were discussions of her mother leaving. If there had been discussions, they probably did not involve Tammy but her grandmother; Tammy was a child, and decisions were made by the adults of the household. Trusting her mother's decision and her grandmother's ongoing narrative that her mother had gone to Canada to afford her and her siblings a "better life," she was content that someday she would go to visit her mother and ultimately live with her. As Tammy remarked, "This did not hurt me in any way because, whether my mother was present or not, my grandmother took care of all of us."

Tammy explained that "It was a cooperative role between my mother and grandma." Tammy described her grandmother as a loving, nurturing caregiver who took excellent care of her and her two younger siblings. As she said in Patois, "My grandmada took good care of me. She was much like mi mada." Tammy had tears in her eyes as she spoke about her grandmother. Although Tammy's grandmother was good to her, she recounted that she could not fill the void created when her mother left Jamaica. As she explained, "I had my grandmother, she was good to me, but I still wish I had my mother." Tammy described their relationship during the 
separation, recalling that her mother would write and send money to her grandmother. However, she remembered they had no access to a telephone because they resided in the most rural part of Jamaica. It was not equipped with amenities like First World countries had at the time.

Tammy recalled going to Christiana (a Jamaican city) to have her picture taken with her siblings, so that her grandmother could send it to her mother and show her their growth and development. Tammy also mentioned that the outline of her feet would often be traced on "book leaf" (lined paper) and the book leaf mailed to her mother so that she could purchase appropriately sized shoes. She recalled that, because her grandmother was illiterate, Tammy was tasked with writing all the letters that her grandmother dictated to her. The letters included accounts of which sibling was misbehaving at the time and how well they were doing in school.

Although Tammy's mother did not visit Jamaica, she supported them by regularly sending money and barrels twice a year, in the summer and at Christmas time. The barrels contained shoes, clothes, and food items. She recalls that the Christmas barrel was particularly special for her because, not only would she receive fancy clothes, but people in the community would have a fair share of her mother's love because the contents of the Christmas barrels were distributed among community folks. As Tammy recounted, "The older folks, while going to tend to their cattle once in a while, would stop and talk with Granny to ask about my mother, and would often end the conversation that they would continue to support her through their prayers."

At 15 years old, Tammy joined her mother in Canada, and she recalled the transition as emotionally difficult. She missed her grandmother dearly and had joined her mother and her new boyfriend. She recalled that it felt awkward, because she was not aware that her mother had a boyfriend. He, however, did not reside in the home. Her mother was very welcoming and appeared happy that Tammy was finally in Canada with her. Her mother beamed with happiness, 
perhaps because Tammy had finally arrived after six long years away from her. Her mother did not look the same as when she left Jamaica, Tammy recalled. She appeared shorter and older and did not look like the person Tammy saw in the pictures her mother would frequently send. For the first month after Tammy arrived in Canada, her mother spent a lot of time with her, almost catching up on lost memories and trying to paint a picture of how difficult it was emotionally without the children. Tammy recalls her mother telling her she kept the children close to her heart by interacting with and supervising other children in the neighbourhood—unofficially, the same way Granny did while Tammy’s mother was away.

Tammy also recalled her mom telling her she was very sad, but she kept her composure by having a strong Christian faith. When Tammy's mother left, one of her sisters was seven years old and the other was five. This made it more difficult because her younger siblings had no recollection of their mother. Tammy recalled, further, that she arrived in Toronto in early August and soon forged friendships in her new neighbourhood. As she explained, "It was as if the community was waiting for me. It was quite welcoming. All of my mother's friends were excited to meet me and offered up the title as 'Auntie and warned that they would not be happy with nothing less."

The request of her mother's friends to be called Auntie was not new, Tammy recalled, because she called people with whom she had no biological ties as Auntie in her small community in Jamaica. She indicated that, upon her arrival in Toronto, most of the neighborhood families she interacted with were Black and came from the Commonwealth Caribbean. This familiarity provided a nice transition for her and prepared her for activities like taking public transportation, going to the library, attending church, and ultimately school. 
Tammy did not feel that social integration into the community was difficult, because everyone knew she was coming. In addition, her mother's friends and their children had the same experience of migration and separation, which made the process of migration seamless. There were always kids her age knocking on her door, offering to do something or just hang out at a local park. She explained,

My mom's friends had an open-door policy, and they lived a doorway from each other. Although I know that my mother was not present because she was working long hours, there was always one auntie looking out and supervising us as we roamed the neighbourhood.

This situation mirrored so much of what she had experienced living in her small landbased community in Jamaica. As she noted, "People had the same value system as Jamaica." Pausing, she reflected as if she had an aha moment (a sudden insight), by this time her mother was no longer a nanny and was working full time at the "local nursing home taking care of old, rich, white people," as she described her mother's job. Although most parents in her new community went to work, and most worked long hours, Tammy recalled,

There was always an older aunty who lived in the community, who stayed at home because she was either retired or something, and who had unofficially assumed the role of the community auntie, who made sure things were safe for each of us. She would have our mother's number on speed dial, providing documented account of when we were out of line. We also knew unofficially that we could contact her if something serious when down or if we needed to contact our parents.

Living in her rural Jamaican community, the values tend to be different from urban values and even though parents were living in big cities like Toronto they were able to find a community that is supportive of their cultural values. Tammy stated,

Or just as an unspoken rule they would hang out there on Friday evening after a long day at work. In the front of the store there was a display of Caribbean grocery items; but in the back, particularly on a Friday the men would hang out and play dominoes, just like we would do in Jamaica. It would be mostly men, but it appears to help my mother not feeling so alone in this place. We would not 
survive without the support in the community complex. It was also a place that was safe, where they would network and provide word of mouth jobs for people who had just come up, and the ones that were employed would put a good word in to their employer.

Tammy also recalled that:

September had rolled around, and the weather started to have colder evenings, and dusk came really early; three o' clock was pitch dark and it was quite confusing for me because no one explained that it got dark this early. Her Canadian friends had described fall and winter, but it was nothing in comparison to experiencing it. Man, it was cold, even with my coat, gloves and tights under my clothes and it was still cold. I hated the winter because I could not feel my face You could not stand outside like you were in Jamaica and talk, there was no one hanging out; instead everybody stayed inside and that was hard to get use to.

Another thing Tammy noticed was that, during the winter months, it was difficult to get clothing with bright colors; everyone wore dark clothes that were not nice like the bright colors in the stores like Jamaica. She explained that her biggest challenge was going to high school. The teenagers were mean, and it was her first introduction to racism. She explained further,

I did not know that I was considered an inferior person until I attended high school. I was living in an area where they were mostly Blacks, and my association since arriving from Jamaica was with Black people from the Caribbean. I went to a high school where there were predominately whites and a sprinkle of racialized people. I was called names and ostracized by the whites, especially those that were in my class. There was one other boy who was Black, but he stood quietly when they were saying and hurling racial epithets. It's as if he was relieved from the ongoing torture, which he later qualified. It was immensely painful, because it was this feeling of rejection and alienation that I never felt before. After all, in Jamaica no one treated you badly because of the colour of your skin, at least not in my neighbourhood.

Tammy mentioned that her community had always been welcoming and if you treated anyone the way she was treated in school, it would be frowned upon with distain. Yet, school staff did not protect her. She recalled, "As if experiencing racism from my classmates were not enough, it was filtered over in the school's acceptance." Tammy recounted how they had placed her in a lower-level class because they wanted to see how well she could do in English. They 
thought that Jamaicans do not speak English but "dialect," as Tammy explained. She added, “After having my first experiences with racism, I went home and told my mother, who told me that I should tell them that I'm Jamaican, and God had made me this way." Tammy recalled that her mother at the time did not understand the impact of racism or simply had no explanation, because she probably knew the feeling but did not have the language to explain the excruciating pain associated with racism. As Tammy surmised, her mother probably feared that the ugliness of racism would keep her distracted in school.

Tammy recounts how her friends and community members helped her address racism at school:

My friends were very aware and were able to provide a micro-level solution to the problem. One of the older girls from the community, who attended the same school, volunteered to come and get me during lunchtime and recess and made it a point of duty to check up on me with another girl who was from another racialized group, until I was able to empower myself. Getting teachers involved was futile, because they did not understand what was happening or they failed to acknowledge that it was racism. So, we really suffered in silence. I think we had it hard, but my parent's generation I think had it the hardest. My mother never talked much about her early experience with racism. But I can only imagine she did [experienced racism], because the other community aunt spoke vocally about it and openly shared stories of racism.

Tammy explained that her mother had never attributed people's hatred of any sort to the colour of their skin, but rather the content of their character. Tammy added, “I wasn't sure whether this was a coping mechanism or whether it was psychologically debilitating for her, because it brought memories that was disconnected from her feelings in order to stay resilient for herself for me and probably for the community." On the other hand, Tammy felt that the Black community "shielded me from most of the ugliness of racism." She added, "when something did not make sense, it was often put in context by the community 
elders, in conjunction to my history and my ancestral past." Nevertheless, experiencing racism after reuniting with her mother in Toronto helped her to develop resilience:

If this did not do anything else for me, it made me realize what side of the train track I lived on. It made me want to excel in school and, regardless of what my teachers said, I was destined to do well for myself and the community.

\section{Doreen}

Doreen gave her age as 50-plus and she resided in Toronto for most of her life. Recently, she moved out of Toronto when she purchased a house in Brampton. She attended college and has a diploma in the hospitality sector. Doreen reported that her father and mother were married and lived in Jamaica, in a small Bauxite-mining community in Saint Catherine. Later, her father migrated to Canada because he wanted to pursue a career in criminal law. Her mother and father kept in touch, and within a couple of years her mother joined her father in Canada, leaving Doreen and her younger brother in the care of her grandmother and her aunt. Doreen was six years old, and her brother was four. She said that her grandmother lived in the same community but in a different home; they would visit her frequently.

Doreen remembered that her grandmother lived on a big plot of land that was green and lush. She raised chickens, goats, cows, and other domesticated animals. Her aunt resided with her mother (Doreen's grandmother). Doreen's aunt worked at Alcan bauxite plant while she helped to take care of the children. She recalls visiting her grandmother a lot so, so when the time came to live with them, it was no surprise. Doreen recalled that a couple of days before her mother left for Canada, she sat her two children down and told them that she was going to Canada to join their dad. However, she said she would return for them as soon as she could. Doreen remembered that she did not feel emotional or a loss of any sort and trusted her mother's decision, especially since she was going to help to give Doreen and her brother "a better life" by 
joining her father, and also shorten the reunification process. As Doreen remarked, "I understood that she was coming back, as she explained to the family, because we were very close." In addition, she knew her mother would keep her children safe. Doreen continued,

My mother and father had no family in Canada but like most immigrants, they were seeking better opportunities. While in Canada, my father worked in a print shop while my mother worked at a nursing home in the laundry department. Prior to migration, my mother was a primary school teacher and my father worked for the local newspaper, which were fairly good, middle-class jobs in Jamaica. Both parents' education from back home did not matter. They decided to settle for a 'job' to make life better for their family. My mother had the dominant personality, and my father was very reserved and only subscribes to the traditional gender role, which is to work and bring home the money and he didn't get involved with hands-on parenting. My mother would send money often and barrels three times a year. And it would have everything we needed as a child.

Like Tammy, Doreen mentioned that, even though they had fine clothing and the things they needed, she would have preferred to have her mother. Both Doreen and Tammy also communicated with their mothers via letters and limited telephone calls. Doreen commented that, while residing with her grandmother she had not heard her mother's voice in years. However, Doreen's mother received sentiments from her grandmother in the forms of letters. Doreen's grandmother prepared her for eventual reunification with her parents by telling her the things she knew about Canada. She implored Doreen to pick up books from the local library in Jamaica, to learn more about Canadian culture. She recalled her grandmother cautioning her often that, sometime in her life, she would be reunited with her parents and therefore she needed to learn life skills. Doreen remarked, "My experience living with my grandmother and aunt was very positive." Nonetheless, she admitted that her knowledge about Canada was the same as her knowledge about America: idealized, a textbook image.

Six years after her parents left Jamaica, Doreen and her brother joined them at the age of 12. They resided in the east end of Toronto in a middle-class neighbourhood, where her parents 
rented a three bedroom apartment. She explained, "The neighbourhood was very diverse, with different groups of people. I arrived in Canada in the end of November, and I have never experienced this type of cold. Even with layers of clothing I was still cold." She added, "I was also confused with time and why it was dark at 3:00 in the evening." In talking about how migration affected her and her brother, she recounted,

My parents spent long hours at work, and we spent a lot of time indoors, which helped me to develop a stronger bond with my brother. We knew no one in the neighbourhood and would watch the parents and their children from my bedroom window, from the 3rd floor of the 10-storey apartment building. My parents were very private, and there were strict rules around opening the door and going outside without asking them. It was a difficult contrast, coming from a country where we spend a lot more time outside interacting with people. And not being able to do that without your parents' supervision was quite difficult. I felt really isolated, and my brother and I had minimal friends even when we started school.

About going to a new school in Canada, Doreen remembered,

We were enrolled in a Catholic school, and we wore uniforms just like home. The transition was good for the most part. I was able to transition to the same grade as I was while in Jamaica, and there was no discussion to place me in a lower grade academically — at least not that I am aware of. There were several other Black students in my class and, surprisingly, my teacher was Black.

Doreen remembered this teacher vividly and how easy it was to make the transition into school because her teacher understood. She was unapologetic in her strong support of the Black students, and she looked out for us (black students), almost unassumingly taking up the role of the black children's respective r parents. As Doreen described her teacher,

Academics were big on her agenda and grilling us on how important it is to do well academically was her mantra. She had library selection of books that she felt we should read to enhance our English comprehension and awareness of the world.

Doreen's teacher played an important role in her migration process:

She developed a community among us that provided us with resiliency to protect us from the ugliness of racism and modelled for us how we should treat each other and look out for each other. Anyone who attended that school and was 
Black and a new immigrant from the Caribbean or Africa would be introduced to her. The people in that group became my friends, and the students who were there long before me was expected to help us with transitioning.

Doreen's school friends in Toronto taught her things about Canada that augmented what her grandmother implored her to research before coming to Canada. Her brother was also introduced to a black group of students, and her teacher from the school would send home books that were age appropriate for him to read. Doreen recalled her experience at school was her first introduction to Blackness and what it meant to be Black in a North American society while linking this knowledge to my African ancestry. In Jamaica, she was not taught about Black history, let alone her African ancestry. She remembered correcting the teacher that I was not from Africa and that I was Jamaican. She commented, "My colonized history was catching up with me, and I did not realize how little I knew about ancestral history and the link to Africa through the Atlantic slave trade, which had brought my ancestors to Jamaica."

Doreen explained that her grandmother's preparation of her for migration helped her transition to Canadian society. She recalled,

My parents were too busy working long hours to maintain a decent roof over our head and to avoid living in the projects. I supervised my brother most of the time and became his unofficial caregiver, with the understanding that my parents were doing this so that my brother and I could have a 'better life.'

The life skills her grandmother taught her were very valuable after she migrated. She recounted,

Things like cooking, making the bed and tidying the house were no issue. I would write to Granny to let her know what was going on and how her teachings helped to make life easier, especially for the family. Because most evening I would start dinner, and my mother would come and complete it or would dictate over the phone what to do before she takes the subway to get home.

Doreen explained that her grandmother prepared her well for migration and that she holds no ill feelings toward her parents, particularly her mother, because "Granny actually prepared me in a 
way that I understood it from an immigrant perspective. I had no ill feelings towards my mom, because I know she sacrificed her happiness to give me and my sibling a better life."

\section{Discussion}

Most parents who migrate, especially those from Jamaica, attempt to ensure that their children left behind are in kinship/community arrangements, to minimize the disruption in their children's lives after migration. However, despite these arrangements, several of the articles I reviewed indicate that "barrel children" or "children left behind" received little or no emotional and physical nurturance from kin/community caregivers and often experienced abandonment (Crawford-Brown \& Rattray, 1994). This happens even when parents attempt to remain in contact via telephone. Despite their best efforts, contact may be irregular and sometimes fall short of meaningful exchanges between parents and children. The literature also highlights that, when parents in the host countries become aware of the difficulties their children may be encountering with kin/community caregivers, some seem to respond with denial rooted in helplessness. Others lack insight and understanding of the psychological impact of separation on children (Crawford-Brown \& Rattray, 1994). The literature also mentions that, when children, parents, and caregivers are comfortable with the caregiving arrangement, distress can be reduced. However, even under the best circumstances, parents will still worry excessively about their children. In some cases, tremendous feelings of guilt may strain the parent-child relationship when children are reunited with their parents.

The two women I interviewed for this research study reported no major challenges in their reunification process and undoubtedly felt that their reunions were exciting and joyous, because they understood the sacrifices their parents were making for them. 
Tammy remarked that Caribbean people, particularly Jamaicans, understand migration as a way of out of a life of poverty, and that most embrace this narrative. Even though most reunifications have challenges, Doreen and Tammy reported none within their family structures. However, they did describe reunification challenges in interacting with school and other structural systems. Tammy mentioned that she had some struggles with the language, particularly the pronunciation of words and how others perceived her accent, as well as her experience of racism. At her school, staff considered her and other immigrant children to be at a disadvantage compared with their Canadian counterparts. Doreen reported that, although she would have the odd disagreement with her parents, disagreements did not rupture the foundation of her relationship with her mother. She also mentioned that having her grandmother as her constant caregiver, even when her mother was present did not take away from the parenting role of her mother. Instead, she said that her grandmother raised her mother, who in turn co-parented with her grandmother. This co-parenting supported the nurturing role even before she migrated to reunite with her mother.

Although both women reunited with their parents in the height of adolescence and development, neither attributed any psychosocial or emotional experiences in their parent-child relationships to their migration process or parental separation. Tammy spoke briefly about her mother having a boyfriend who apparently did not live with her, so the reconstitution of the family was not entirely impacted. She mentioned no step-siblings, and she did not have to figure out how to fit in with the family because she already knew where she stood. Her mother worked late, and she did not feel alone because she had contact with her mother throughout the day. She described feeling like her situation was the norm, because all the other children she hung out with during the day had parents who were also at work, leaving them to be supervised by the 
community auntie. She also mentioned that she caught up with her mother mostly during dinner. Her mother always told her children how guilty she felt leaving them, but it was to provide a "better life."

Both Doreen and Tammy talked about understanding their mothers' decisions to come to Canada. Both explained that it took time for them to understand how their mothers did things and sometimes there were communication challenges. These, however, would be worked out, sometimes with their grandmothers' participation.

It is important to highlight the limitations of this study. The first is the small number of participants. I acknowledge that it does not provide a diverse representation of self-identified Jamaican immigrants living in Toronto whose parents migrated leaving family members to care for them. A second limitation is my social location and direct experience with the barrel-child phenomenon. This may have biased my interpretation of the data.

Moving forward, future research could explore the experiences of more women from Jamaica, providing equal representation of different Jamaican racial, class, and geographical (urban/rural) identities. Other identities absent from the study were non-heterosexual identified individuals and those living with a disability. Probably, these identities did not come up in the interviews, due to the questions I asked. A final limitation was the lack of response to my invitations to participate in the study, because of the Jamaican negative feelings about research. Many of the studies I reviewed indicate that, when separation and migration are planned in a timely manner, the negative emotions associated with separation can be cushioned with ongoing preparation and by parents explaining that they are leaving to provide their children a better life.

Sociocultural understanding of migration 
Maternal separation due to immigration is not new to many Caribbean families, particularly Jamaicans. Parents, especially mothers, often harbor guilt about leaving their children behind. The guilt is even more pronounced when children are left with strangers and the experience is negative (Thomas-Hope, 1992). Research has shown that, when the experience is negative, families tend to link children's difficulties and their separation from parents. Although the two participants I interviewed had positive experiences, it is important to highlight the diversity in the experiences as it creates a better understanding of the barrel-children phenomenon. For the parents of Tammy and Doreen, the decision to migrate to Canada took two different forms.

Doreen's mother planned it and sat down to tell her children, while Tammy's mother left without any formal planning. The nature of Jamaican family life sometimes not only facilitates maternal immigration but accommodates and perpetuates it. A culture of immigration creates sociocultural narratives embodying an understanding that, when parents leave for industrialized countries such as Canada, it is for a "better life."

Doreen recalled, "She told us it was for a better life and to afford a better life for me and my brother." This finding supports the most common sociocultural understanding of immigration in Jamaica, reinforced by kinship networks and family structures and creating a widely accepted practice. The sociocultural understanding of migration helps contribute to Jamaica's fluid way of life, which may or may not be unique. On the other hand, it facilitates migration in which children can be left behind, creating a generation of barrel children. In Jamaica, most children are raised by extended family members, and these children sometimes develop attachment issues later in life.

\section{Communication}


Maintaining communication during mother-daughter separation is integral to the survival of the relationship. The two women I interviewed did not directly speak to their mothers during separation but communicated with their mothers only through letters. Both women are from small, rural communities in Jamaica, which at that time did not have telephone service. In most of the literature I reviewed regarding Bowlby's attachment theory, he suggests that, if there is no communication between the mother and the child or if the communication stops, the child is likely to become angry with the mother. Communication keeps the image of the mothers alive for the child. However, although both of my participants indicated that they did not have direct contact with their mothers, they continued to have positive mother-daughter relationships even after their reunification. Both credited the ongoing contact with their grandmothers and the continued nurturing these family members provided in the absence of their mothers.

Chamberlain (2001) argues that the importance of grandparents, especially grandmothers, crosses both class and geographical boundaries. Grandmothers' nurturing role is not merely a response to economic circumstances but central to the family, especially in cultures where mothers and grandmothers share the responsibilities of child care. As Doreen explained, "My grandmother took care of me, and I don't remember when I did not have her as my caregiver. She took care of us, and everything I know, I learnt it from my grandmother."

Communication with grandparents was also important for both participants. Good communication also helped them obtain adequate care. Tammy was cared for by her grandmother, while Doreen was cared for by her grandmother and maternal aunt. In both cases grandparents were emotionally available during and after separation and played an integral role in keeping the family together. This reflects similar findings in the literature I reviewed and 
highlights matricentic roles and shows the importance to sustaining some form of communication with mothers during separation.

\section{Father involvement}

Doreen's father migrated first, and her mother joined her father two years later, while Doreen remained in Jamaica. Both shared responsibility for taking care of the children. However, Doreen noted that, even though her father was present in the home, her mother did most of the household chores childcare work. Her father played the traditional male role by taking care of them financially, without sharing any responsibility in parenting. Some of the literature reviewed for this study indicated that, when both parents are in the home after the children reunite with mothers, reunification is less stressful. However, even though Doreen's father was not actively involved in raising his children, her mother did not seem to be overly concerned. She seemed to accept this situation by taking full responsibility for the family. In most Jamaican families, mothers are the glue that keeps families together. As Tammy reported, her father did not live in her home; he only supported the family financially. This highlights the importance of the maternal role in barrel children's lives, whether mothering is biological or communal.

\section{Support/Community}

Doreen found it difficult, coming from a country where children spend a lot of time outside interacting with people, not being able to do that in Canada without a parent's supervision. Tammy, however, noted that her new community in Toronto shielded her from most of the ugliness of racism.

Both participants shared small-town community values while living in Jamaica. One was able to experience the same kind of community support, supervision, and cultural understanding in her new community to help with her transition. The other participant was unable to experience 
all aspects of the community, which made it a little more difficult for her and her brother to transition. She was, however, able to find community in the school setting with the other immigrant children and a Black teacher who helped to foster community. The participants' experience clearly highlighted the importance of community connection during and after transition, and the role of community during migration. These findings are relevant to social integration into Canadian society. 


\section{CHAPTER 6. CONCLUSION}

This major research paper explores the effect of migration on female children left behind in Jamaica and their social integration after reunification with their parents, particularly mothers, in Toronto, Canada. To obtain narratives of lived experiences, interviews were conducted with participants who were left behind, who were barrel-children. The aim of the research was to find out how children dealt with separation from their mothers, what challenges these children encountered in their integration into Canadian society, and what life was like after reunification with their mothers.

The literature reviewed for this study highlight that people often migrate for economic reasons and, in the context of Jamaica, to create a 'better life' for their families. The implications of migration are, however, negative in some instances where children left behind are sexually abused by members of their households or others from the community. In contrast, the two participants interviewed for this study indicated that their experiences as barrel children were good, and they were well taken care of by their grandmothers and other family members. This study also highlights the challenges faced by immigrants, causing delays in the reunification process. Canadian policies on Caribbean immigration limited the areas in which these immigrants could find employment. Participants' accounts of the hardships that their mothers faced to send home money and barrels to take care of them, illuminate the reasons for separation and made participants more understanding of the plight their mothers faced. For example, one participant's mother, who had been a teacher in Jamaica, took a job in the laundry department of a nursing home just to give her children left behind a better life.

Immigration to developed countries such as Canada from places like Jamaica comes with some challenges. One participant spoke of her first exposure to racism and the alienation this 
created before others from her community helped empower her to deal with racial discrimination. Her alienation was compounded by the school administration's ignorance of the language spoken in Jamaica, since they thought Jamaicans spoke only dialect. The other participant was more fortunate; she had a Black teacher, who created a safe community and empowered Black students to look out for each other and assist newcomers with the transition process. This study provides empirical evidence that the barrel-children phenomenon in many cases cultivates positive attributes, such as resiliency.

How then can Jamaican immigrants better prepare for the challenges they are likely to face in integrating into the Canadian society? First, knowledge is power. Mothers need to be open in sharing their own situation with their children so that, when they encounter racism, it is no surprise. Second, mothers who migrate leaving children behind need to prepare their children for the Canadian education system by gathering information of what is expected prior to coming to Canada. As one study participant pointed out, complaining to your white teacher that you are being ostracized has no effect, so the Black community has to empower itself in order to survive.

This major research paper contributes to the field of social work a better understanding of cultures such as Jamaica's and may help social workers in serving Black families. Many counselors and therapists in Canada are still not familiar with Jamaican or Caribbean migration culture, family structure, and child socialization practices. Those who work with Jamaican children and families need psychosocial assessment tools that incorporate Jamaican separation and migration stories. This study provides a rich understanding of the barrel-children phenomenon, particularly the mother-daughter relationship, which has been under-researched. It is hoped that this MRP increases awareness and stimulates conversation to support more research 
in this area. Such research will help to inform social workers whose clients have been barrel children. 


\section{APPENDIX A}

\section{RECRUITMENT FLYER}

My name is Andrea Lawrence. I am currently completing my Master of Social Work degree at Ryerson University. As part of the requirements of my degree program, I am required to complete a Major Research Paper. I am working under the supervision of Dr. Gordon Pon, Associate Professor in the School of Social Work at Ryerson University.

The topic of my research paper is exploring the Impact of "Barrel children" phenomena on the social integration of adult children in Toronto Ontario. The three questions that will be used to guide my research are as follows:

- How do adult children experience separation during and after the separation from their mothers?

- What are some the challenges adult barrel children experience in terms of integration into Canadian society?

- After been reunited what are some the experiences of the mother daughter relationship?

I intend to interview several- Jamaican adult Immigrants who are living in Toronto, Ontario. In interviewing this demographic, I hope to uncover diverse perspectives of their challenges/ acceptance of their experiences to socially integrate in Canadian society and linking it the broader institutions such as immigration and other structural systems.

If you are a Jamaican Immigrant who may be interested in this study, please have individuals contact me for more information. 


\section{APPENDIX B}

\section{INTERVIEW GUIDE}

\section{The impact of "Barrel children" phenomena on the social integration of adult children in Toronto Ontario.}

\section{Interview Guide: Participants}

The following is the interview guide I used to interview Tammy and Doreen one-on-one for the research study.

\section{Participants Background}

Can you tell me a bit about yourself? Where were you born? When did you migrate to Canada? How do you self-identify? Your age?

- What did your mother tell you about her plans to come to Canada?

- What did you remember about your relationship with your mother before she left to come to Canada?

- How involved was your father while your mother was away?

- How well did you know the person who cared for you before your mother left to come Canada?

- How would you describe your relationship with the person who cared for you when your mother was away?

- How did this person help with the plans for you to come to Canada to live with your mother?

- How often did you make trips to see your mother?

- How often would you speak or received letters from your mother?

- How would you describe your experience growing up away from your mother?

- Tell me about your transition into school and your experience with the education system?

- Do you think you were treated accepted when you attended school?

- How your school does grades, prior to coming to the Canada, compare with your grades after migrating to Canada?

- Tell me about some of the things that occurred when you were not living with your mother?

- Tell me about some of the things that occurred since you came to live with your mother?

- When you thought about coming to Canada to live with your mother, how did you feel and what did you imagine would occur?

- What's your relationship with your mother like now?

- Before we conclude, is there anything else that you would like to discuss or, anything important that you want to mention? 


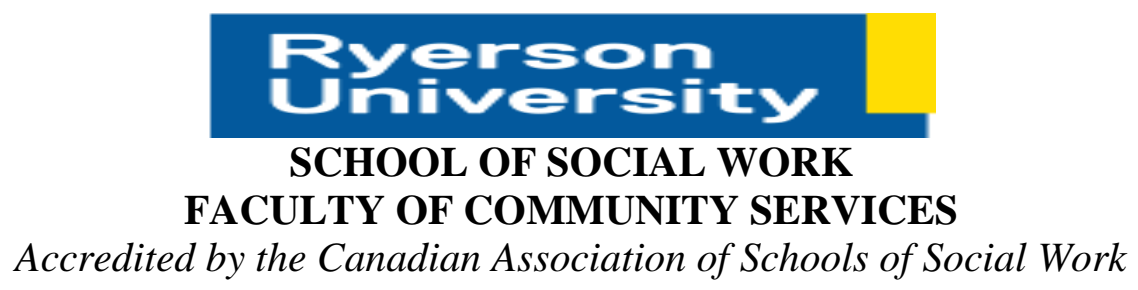

Consent Agreement

You are being invited to participate in a research study. Please read this consent form so that you understand what your participation will involve. Before you consent to participate, please ask any questions to be sure you understand what your participation will involve.

Study: The Impact of "Barrel children" phenomena on the social integration of adult children in Toronto Ontario.

\section{INVESTIGATORS:}

This research study is being conducted by Andrea Lawrence, School of Social Work, and Social Work student. The supervisor of this research study is Gordon Pon, MSW, PhD at Ryerson University.

If you have any questions or concerns about the research, please feel free to contact, Andrea Lawrence at, a3lawren@ ryerson.ca or Dr. Gordon Pon at 350 Victoria Street, Toronto, ON M5B2K3, 416-979-5000, ext. 4786; g2pon@ ryerson.ca

\section{PURPOSE OF THE STUDY:}

This study is designed to explore the experiences and impact of the "barrel children" phenomena on the social integration of adult children living in Toronto, Ontario. The three questions that will be used to guide my research are as follows:

- How do adult children experience separation during and after the separation from their mothers?

- What are some the challenges adult barrel children experience in terms of integration into Canadian society?

- After been reunited what are some the experiences of the mother daughter relationship? 
I am completing this research to complete my major research paper requirement of my Master of Social Work degree. The results will contribute to my major research paper.

There will be 2-3 research participants being recruited for this study. The eligibility requirements to identify prospective participants are:

- Must be Jamaican.

- Participant must reside in Toronto.

- Participant must be a minimum 18 years old who had migrated from Jamaica and reunite with their mothers in Canada.

\section{WHAT YOU WILL BE ASKED TO DO:}

If you volunteer to participate in this study, you will be asked to do the following:

\section{CONSENT FORM}

1) Sign the Ryerson University consent form. Take the time to read this form and ask questions about anything that you do not understand. After you have read the consent form and if you accept to be a participant in the study, please sign the areas requiring your signature.

\section{ARRANGE A TIME TO MEET}

2) Participants will be made aware at the recruitment stage that the interview location can take place in a secure room at the local library in which aural and visual privacy can be ensured due to the possibility of sensitive information being shared. At this same time, participants will be informed that they may choose their own preferred location for the one-time interview to take place (including their personal residence). Should they decide upon this latter option they will be instructed to ensure that their preferred location ensures both aural and visual privacy due to the possibility of sensitive information being shared.

\section{REVIEW INTERVIEW GUIDE}

3) Reviewing the interview guide prior to meeting the researcher for the interview. Take the time to read the interview guide to see what kinds of questions are going to be asked during the interview. If you have any concerns with the interview questions, this would be a good time to address them with the researcher.

\section{MEET FOR THE INTERVIEW}

4) Meet with the researcher at the agreed interview time. Interviews will last between 2-3 hours in length. There will only be one interview for this research study.

\section{REVIEW TRANSCRIPTION}


The audio recordings will be password protected on the audio device and uploaded to password protected audio files. These audio files will be deleted once the transcriptions are completed which is anticipated to be within a week of the interview being audio-recorded. At this point, the transcriptions will be kept as password protected files up until the final draft of the paper is completed and submitted to the School of Social Work of Ryerson University - this is anticipated for mid-May 2019. Once the paper is submitted to the School of Social Work of Ryerson University the transcriptions will be destroyed. The transcriptions are only kept until final publication for the purpose of my being able to review them and write my paper.

\section{APPROVE FINAL RESEARCH PAPER}

5) Before the final research paper is submitted to Ryerson University School of Social Work, you will have the opportunity to review the document to ensure you' re in support of the way your particular interview has been reflected in the research and to ensure that there is no misrepresentation of the information.

\section{POTENTIAL BENEFITS:}

There can be no guaranteed benefits from participating in this study. However, the experiences and knowledge shared by you will help to raise consciousness and create knowledge about a topic that is under researched.

WHAT ARE THE POTENTIAL RISKS TO YOU AS A PARTICIPANT:

$\underline{\text { Psychological risk (e.g. feeling anxious, upset or uncomfortable) }}$

Questions and topics that come up during interviews about your experiences may trigger uncomfortable emotions. The risk of this happening is medium to low risk, and community resources will be provided at the end of the interview.

\section{CONFIDENTIALITY:}

Everything pertaining to the study will be kept confidential and all transcriptions will be kept in a password protected file. All participants' names will be pseudonyms unless participants request to use their real names. Participants will be reminded about confidentiality before and after interviews to ensure they understand that their names will not be used in the study. They will be advised that if they have any questions or concerns that they can contact the researcher at anytime. No personal information of identity will ever be included in the completed research publication. Participants will be asked to review/edit their interview transcripts as well as approve the final research paper to ensure they are comfortable with the information pertaining to them in the document.

Information in this study will not be released to any other party for any reason. The audio recordings and interview transcriptions will be kept in secured file on a computer in the 
researcher's home that only the researcher has access to. These files will be password protected in addition to the password needed to be able to log onto the computer. These files will remain on the researcher's computer until the final draft of the major research paper is complete (estimated completion, May 2019). Once the final draft is submitted to the School of social work all files and transcriptions will be deleted from the computer and deleted a second time if they are put in the recycling bin. The audio files will be deleted once the transcriptions have been complete. I anticipate completing the transcriptions within two weeks of each interview. The transcriptions/data need to be kept until the final paper is submitted for me to review and make necessary changes with the information. It also gives research participants the opportunity to listen to the audio and review their transcription anytime they would like to during the research. You have the right to review the audio and transcriptions of interviews anytime that you would like. The transcriptions are only kept until the final publication for my being able to review them and write my paper. Estimated completion date is May 2019.

\section{PARTICIPATION:}

As a research participate you will not be paid to participate in this study

\section{COSTS TO PARTICIPATION:}

If interviews are held at a local library there may be parking cost. You will be reimbursed of these costs on the day of the interview.

\section{COMPENSATION FOR INJURY:}

By agreeing to participate in this research, you are not giving up or waiving any legal right in the event that you are harmed during the research.

\section{VOLUNTARY PARTICIPATION AND WITHDRAWAL:}

As a research participant, your participation is entirely voluntary. As a research participant, you have the right to remove yourself from the study at any time and you have no obligation to complete it. Withdrawal from the study will not influence future relations with the researcher Andrea Lawrence or Ryerson University. You have the right to remove yourself from the research at any time and you have the right to request that your interview be destroyed and not used in the study. During the interview, you have the right to refuse to answer any questions that you do not want to discuss or which makes you feel uncomfortable.

\section{QUESTIONS ABOUT THE STUDY:}

If you have any questions about the research please contact at me Andrea Lawrence, Social Worker, a3lawren@ ryerson.ca, or Gordon Pon, research supervisor MSW, PhD, Ryerson University, 350 Victoria Street, Toronto, Ontario M5B 2K3, 416-979-5000, ext. 4786g2pon@ryerson.ca 
This study has been reviewed by the Ryerson University Research Ethics Board. If you have questions regarding your rights as a participant in this study please contact:

Research Ethics Board

c/o Office of the Vice President, Research and Innovation

Ryerson University

350 Victoria Street

Toronto, ON M5B 2K3

416-979-5042

rebchair@ryerson.ca 


\section{REFERENCES}

Adams, C. J. (2000). Integrating children into families separated by migration: A CaribbeanAmerican. Journal of Social Distress and the Homeless, 9(1), 19-27.

Amoah, J (1997). Narrative: The road to black feminist theory. Berkeley Women's Law \& Justice, 12, 84-102

Bakan, A., \& Stasiulis, D. (2003). Negotiating citizenship: Migrant women in Canada and the global system. Toronto: Springer.

Bowlby, J. (1973). Attachment and loss. Vol. II. Separation: Anxiety and anger. London: Penguin Books.

Cassidy, J., Jones, J. D., \& Shaver, P. R. (2013). Contributions of attachment theory and research: A framework for future research, translation, and policy. Development and Psychopathology, 25(4, Pt 2), 1415-1434.

Chamberlain, M. (2001). Migration, the Caribbean and the family, Caribbean families in Britain and the trans-Atlantic world (pp. 32-47). New York: Routledge

Chance, L. (2012). Stay: Migration and the Caribbean. Caribbean Quilt, 2, 202.

Connolly, F. M., \& Clandinin, D. J. (2000). Narrative inquiry: Experience and story in qualitative research. San Francisco, CA: Jossy-Bass.

Collins, P. H. (1993). Black feminist thought in the matrix of domination. Social theory: The multicultural and classic readings (pp. 615-625). Boston: Unwin Hyman.

Conway, D. (1991, January). Migration in the Caribbean. In Yearbook. Conference of Latin Americanist Geographers (pp. 91-98). Austin Texas. Conference of Latin Americanist Geographers.

Cortes, R. (2008). Children and women left behind in labour sending countries: An appraisal of social risks. New York: UNICEF.

Crawford-Brown, C. (1999). The impact of parenting on conduct disorder in Jamaican male adolescents. Adolescence, 34(134), 417-36.

Crawford-Brown, C., \& Rattray, M. (1994). The "barrel children" of the Caribbean: The sociocultural context of the migrant Caribbean family. Mona, Jamaica: Department of Sociology and Social Work, University of the West Indies, Institute of Social and Economic Research.

Crenshaw, K. (1989). Demarginalizing the intersection of race and sex: A Black feminist critique of antidiscrimination doctrine, feminist theory and antiracist politics, University of Chicago Legal Forum, 139-167.

Creswell, J. W. (2007). Qualitative inquiry and research design: Choosing among five approaches. Thousand Oaks, CA: Sage. 
Creswell, J. W., Poth, C. N. (2018). Qualitative inquiry and research design: Choosing among five approaches. $4^{\text {th }}$ Ed. Thousand Oaks, CA: Sage

Dwyer, S. C., \& Buckle, J. L. (2009). The space between: On being an insider-outsider in qualitative research. International Journal of Qualitative Methods, 8(1), 54-63.

Ferguson, J. (2007). Migration in the Caribbean: Haiti, the Dominican Republic and beyond. London, UK: Minority Rights Group International.

Fraser, H. (2004). Doing narrative research: Analyzing personal stories line by line. Qualitative Social Work, 3(2), 179-201.

Gibson, P. (2000). African American grandmothers as caregivers: Answering the call to help their grandchildren. Families in Society: The Journal of Contemporary Social Services, 83(1), $35-43$.

Grinberg, L., \& Grinberg, R. (1984). A psychoanalytic study of migration: Its normal and pathological aspects. Journal of the American Psychoanalytic Association, 32(1), 13-38.

hooks, B. (1984). Feminism: A movement to end sexist oppression. In Equality and feminism. Boston, MA: South End Press.

Hsiung, P. C., \& Nichol, K. (2010). Policies on and experiences of foreign domestic workers in Canada. Sociology Compass, 4(9), 766-778.

James, S. M. (1993). A possible black feminist link to social transformation? Theorizing black feminisms: The visionary pragmatism of black women, 44.

Larmer, B. (1996, February19). Jamaican children left behind by mothers in the US Newsweek, 127(8), 45.

Macklin, A. (1991). Foreign domestic worker: Surrogate housewife or mail order servant. McGill Law Journal, 37, 681.

McCarty, T. L. (2004). Dangerous difference: A critical-historical analysis of language education policies in the United States. Medium of instruction policies: Which agenda? Whose agenda (pp. 71-93). Tucson .

Pardeck, J. T. (1984). Multiple placement of children in foster family care: An empirical analysis. Social Work, 29(6), 506-509.

Riessman, C. K. (2003). Analysis of personal narratives. In Inside interviewing: New lenses, new concerns (pp. 331-346). Thousand Oaks, CA, US: Sage Publication, Inc.

Riessman, C. K. (2008). Narrative methods for the human sciences. Thousand Oaks, CA, US: Sage Publications, Inc.

Seeman, M. V. (2011). Canada: Psychosis in the immigrant Caribbean population. International Journal of Social Psychiatry, 57(5), 462-470. 
Smith, A., Lalonde, R. N., \& Johnson, S. (2004). Serial migration and its implications for the parent-child relationship: A retrospective analysis of the experiences of the children of Caribbean immigrants. Cultural Diversity and Ethnic Minority Psychology, 10(2), 107.

Smith, L., \& Grant, E. R. (1996). Immigration reform: Seeking the right reasons. Mary's Law Journal, 28, 883.

Solórzano, D. G., \& Yosso, T. J. (2002). Critical race methodology: Counter-storytelling as an analytical framework for education research. Qualitative Inquiry, 8(1), 23-44.

Stack, C. B. (1997). All our kin: Strategies for survival in a black community. New York: Basic Books.

Thomas-Hope, E. M. (1992). Explanation in Caribbean migration: Perception and the image: Jamaica, Barbados, St. Vincent. George Town: Macmillan Caribbean.

United Nations Children's Fund (UNICEF). (2008). the state of the world's children 2009: Maternal and newborn health (Vol. 9). UNICEF.

Wane, N. N. (2000). Reflections on the mutuality of mothering: Women, children, and other mothering. Journal of the Motherhood Initiative for Research and Community Involvement, 2(2) 110.

Whiting, L. S. (2008). Semi-structured interviews: Guidance for novice researchers. Nursing Standard, 22(23).

Williams, C. (1985). The role of women in Caribbean culture. Barbados: University of the West Indies, Women \& Development Unit, Extra-Mural Department. 